\title{
Effect of Self-Efficacy Enhancing Intervention Training on Clinical Health Status of Diabetic Patients at High-Risk for Leg Problems
}

\section{Zeinab Hussen Ali}

Helwan University, Cairo, Egypt

"Corresponding author: Hussen Ali Z, Faculty of nursing, Helwan university, Cairo, Cairo 002, Egypt, Tel: 0020122492308; E-mail: salmame20003@yahoo.com

Received date: Jan 13 2016; Accepted date: Mar 21, 2016; Published date: Mar 30, 2016

Copyright: @ 2016 Hussen Ali Z. This is an open-access article distributed under the terms of the Creative Commons Attribution License, which permits unrestricted use, distribution, and reproduction in any medium, provided the original author and source are credited.

\begin{abstract}
Egypt has more diabetic individuals than any other country, with high incidence of foot problems and amputations. This study was aimed at evaluating the effect of a self-efficacy enhancing intervention training (SEEIP) on the clinical health status of diabetic patients at high risk for leg problems. The study was conducted in the diabetic outpatient clinic in Ain-Shams Specialized University Hospital in using a randomized controlled trial study design. It included a sample of 60 diabetic patients randomized an intervention group of 30 patients to attend the program and an equal control group following the routine diabetic care in the setting. The data collection tools were an interview questionnaire sheet, and adiabetes clinical/lab form, the self-efficacy assessment form for diabetic patients, and a leg physical assessment sheet. The study was carried out through preparatory, assessment, planning, implementation, and evaluation phases. The training intervention consisted of five efficacy-enhancing sessions at weekly intervals. For evaluation, two posttests were carried out at one and six months after the end of the program. The work was from September 2014 to August 2015. The study revealed statistically significant improvements in the study group at the post- and follow-up in lower limb physical findings $(p<0.001)$, compliance with medications, more days of intake of medications, of following diet, exercise, and practicing foot care during last week $(p<0.001)$, perception of health, and self-confidence $(p<0.001)$, hypertension $(p<0.001)$, random blood sugar $(p<0.001)$, glycated $\mathrm{Hb}(p<0.001)$, and total cholesterol $(p=0.001)$. There were statistically significant positive correlation between the scores of self-confidence and foot self-care $(r=0.96)$, and between the number of abnormal signs and the level of $\mathrm{HbA} 1 \mathrm{c}$, while the total number of abnormal signs correlated negatively with the score of self-confidence and foot self-care. The level of $\mathrm{HbA} 1 \mathrm{c}$, it correlated negatively with the scores of self-confidence and foot self-care. In conclusion, increasing diabetic patients' self-confidence and self-efficacy can improve their self-care practices, with subsequent positive impacts on their general and feet health status and diabetic control. The implementation of self-efficacy enhancing training programs is recommended with the use of the developed illustrated booklet as an educational aid for diabetic patients whom at risk for leg problems. More research is needed to investigate the longterm effect of such educational interventions.
\end{abstract}

Keywords: Diabetes mellitus; Self-efficacy; Clinical health status; Leg problems

\section{Introduction}

Diabetes mellitus is a chronic disease due to defects in insulin production, insulin action, or both. Worldwide, the number of cases of diabetes has been estimated to be 171 million, and by 2025, this number is projected to reach 366 million [1]. Diabetic patients are at high risk for many serious and costly complications such as heart disease, kidney failure and blindness, and foot complications, making it a public health problem worldwide [2,3]. This latter complication may take the greatest attention due to its dreadful possible outcome of amputation, with its negative consequences on the patient, family, healthcare system, and society $[4,5]$.

Foot ulcers develop in approximately $15 \%$ of individuals with diabetes and foot disorders are a leading cause of hospitalization among them [6]. Eighty-five percent of lower limb amputations in persons with diabetes are preceded by foot ulcers, indicating that foot ulcer prevention and management are of paramount importance. The most common factors related to development of foot ulcers are peripheral neuropathy, minor foot trauma and foot deformities and infection [7]. Diabetic foot ulcers are complex and multi-factorial in nature, often involving ischemic and neuropathic components, the latter of these two occurring within $10-15$ years of diagnosis in $50 \%$ of diabetic patients [8]. The main issue in diabetes management is to prevent microvascular and macrovascular complications and to decrease mortality and economic costs [9]. To achieve these goals, diabetic patients have to engage in their self-care practice [10].

Patient education is essential in the empowerment of people with diabetes, helping them to develop an effective partnership with healthcare professionals, which is key to achieve effective care. Optimal diabetes management, daily foot care, education for the person with diabetes and their family, along with screening and risk assessment are all critical aspects for prevention of diabetic foot ulcer [11,12]. For effective education of diabetic patients, especially those at high risk of complications it is crucially important that healthcare professionals develop their understanding of the patient perspective to increase their self-confidence and self-efficacy. In addition, a necessary adjunct to the patient perspective is the need to recognize those patients who are at a high risk of complications [13].

Traditional diabetic education focused on the transfer of information or skill. However, educational programs based on selfefficacy theory for self-management of diabetes are needed since patient's self-care depends on patient's education, empowerment and self-monitoring results of self-care [14]. Self-efficacy is a person's 
perception of own ability to perform actions and control situations, with a feeling of empowerment. According to Landers and Arent in 2012, self-efficacy depends on primary and second hand experiences, verbal encouragement, and physiological and affective states. Thus, diabetic patients with enhanced self-efficacy would be more able of self-care management [15]. However, still more research is needed to provide robust evidence of the effectiveness of patient education in the prevention of diabetic foot complications [16].

\section{Significance of the study}

In Egypt, $12 \%$ of the adult population aged 20-79 years have diabetes. However, because Egypt has a relatively young population, this is corrected to $15 \%$ when used to compare with other countries [17]. The alarming fact is that Egypt has more diabetic individuals than any other country [18], and the incidence of foot problems and amputations remains very high, accounting for up to $20 \%$ of diabetesrelated hospital admissions. This can be easily attributed to several practices prevalent in Egypt, such as barefoot walking, inadequate facilities for diabetes self-care practices, low socioeconomic status, and illiteracy [19]. The burden of diabetic foot is set to increase further in the future, as its contributory factors such as peripheral neuropathy and peripheral vascular disease are present in more than $10 \%$ of cases at the time of diagnosis [20].

The researcher observed an increasing trend of the diabetic patients attending the medical clinic in the study setting complaining of lower limb vascular problems. This might be the result of lack of proper selfcare practices due to low self-confidence and knowledge about diabetes. Hence, it was thought that with adequate attention to improving patients' knowledge and self-care skills through a selfefficacy enhancing intervention program these problems could be reduced.

\section{Aim of the study}

The study aim was to determine the effect of self-efficacy enhancing intervention training on clinical health status of diabetic patients at high-risk for leg problems. It was hypothesized that, compared with those who did not attend the program, the diabetic patients who attend the program will have 1) better compliance, and undertake diabetic self-care activities more frequently, and 2) will have better lower limbs health status, blood pressure and relevant laboratory findings.

In this study, the working definitions applied are as follows. Selfefficacy enhancing intervention (SEEIP): It is a program designated by the researcher to be used to enhance the diabetic patients' selfconfidence and ability of caring for themselves. Diabetic self-care activities: the self-care measures that patients undertook over the preceding seven days; these included foot care, exercise, suitable diet, testing blood glucose and taking medications and Clinical health status: The outcomes that developed and measured by the researcher to assess diabetic patient's leg status and laboratory findings pre and after implementation of the program.

\section{Theory of the study}

This study based on self-efficacy theory which states, that people generally will only attempt things they believe they can accomplish and won't attempt things they believe they will fail [21] as well Bandura in 1985 [22] stated that, self-efficacy is based on self-confidence, It requires the mastery of skills, the modelling of the educator, and social support.

\section{Subjects and Methods}

\section{Study design and setting}

The study was conducted in the diabetic outpatient clinic in AinShams Specialized University Hospital in Egypt. A randomized controlled trial study design was used with a pre-test and post-tests after five weeks and six months of the intervention.

\section{Subjects}

A purposive sample of 60 diabetic patients following their diabetic care in the study settings were selected. The inclusion criteria were age between 20 and 60 years, having type- 2 diabetes, at high risk for diabetic foot as identified by the risk assessment sheet. Those with actual diabetic foot ulcers or gangrene were excluded. The patients were randomized to an intervention group of 30 patients who were to attend the program and an equal control group following the routine diabetic care in the setting, using the table of random numbers. The sample size was large enough to demonstrate an improvement of 1 point or more in patients' self-care with a variance 1.5 at $95 \%$ level of confidence and $80 \%$ power, taking into account an expected dropout rate of approximately $20 \%$.

\section{Data collection tools}

The researcher used four different tools for data collection. These were an interview questionnaire sheet, adapted and modified by the researcher from La Clinica de LA Raza in 2009 [23], and a diabetes clinical/lab form and a leg physical assessment sheet developed by the researcher. In addition to the self-efficacy assessment form for diabetic patients adopted from Stanford Patient Education Research Center 2009.

1. Interview questionnaire form: This tool included four sections. Section 1) for patient's socio-demographic data such as age, sex, marital status, education, job, smoking, etc., followed by section 2) for the medical history such as the duration of the disease, family history, etc. and section 3) was for diabetes self-care activities. It included questions about diet, exercise, blood sugar testing, foot care, and smoking, and section 4) was for assess compliance with medication, and self-care recommendation in addition to questions about the number of the days of the preceding week were these self-care activities were fulfilled to assess compliance. Scoring system. Each item was checked as "always done," "sometimes done," or "never done." These were scored 2, 1, and 0 respectively with a maximum score 14 and minimum zero. The tool has a high reliability with Cronbach alpha coefficient 0.933 .

2. Diabetes clinical/lab form: This tool was developed by the researcher and constituted two parts, first part to determine patient's clinical health status. It included assessment of the body mass index (BMI), blood pressure. Second part was to assess the results of relevant laboratory tests such as random blood sugar, glycated hemoglobin (HbA1c), total cholesterol, serum creatinine, and blood urea. The tool has a high reliability with Cronbach alpha coefficient 0.875 .

3. Physical assessment sheet for diabetic patient's leg: This was developed by the researcher based on the related literature to 
assess the diabetic patient's leg for any problem or deterioration. It included assessment of the leg pulses (femoral, posterior tibial, popliteal and dorsalis pedis), skin changes, pain, lower limbs edema, and sensation of tough and temperature. Each item was cheeked as normal or abnormal. A patient having any abnormality in these items was considered "abnormal" in the item. In total, any patient having any abnormality in one of the items was considered "abnormal." The tool has a high reliability with Cronbach alpha coefficient 0.954 .

4. Self-efficacy assessment form: this tool was developed by the Stanford Patient Education Research Center in 2009 to determine patient's self-confidence regarding dealing with own diabetic problems. The tool has a high reliability with Cronbach alpha coefficient 0.934. It is composed of eight statements such as "do all the things necessary to manage your condition on a regular basis," "follow your meal plan when you have to prepare or share food with other people who do not," and "judge when the changes in your health mean you should visit the doctor." The patient checks his/her response on a 10-point continuous scale from "extremely not confident," to "extremely confident." The points of the eight items are summed-up and averaged to give a maximum score of 10 so that a higher score means more selfconfidence.

\section{Methods}

The study was carried out through preparatory, assessment, planning, implementation, and evaluation phases. The program implementation and related data collection extended over a period of one year from September 2014 to August 2015.

\section{Preparatory phase}

The researcher obtained official permissions to carry out the study from responsible authorities. The data collection tools were adopted and prepared by the researcher after review of related literature. They were face and content-validated by a jury of five experts in medicalsurgical nursing and medical specialists, and modifications were done accordingly.

\section{Pilot study}

It was carried out on 10 patients from the same setting to assess their feasibility and applicability. The tools were finalized based on the pilot study results, and the pilot subjects were not included in the main study.

\section{Assessment phase}

The aim of this phase was to collect patient's data as well as to identify individualized learning needs in order to design the suitable training program. The researchers recruited the patients, and carried out individual interviewing and physical assessment using the prepared forms. The patients were then randomized to either the study (intervention) or control groups.

\section{Planning phase}

Based on the information obtained from the assessment, and in the light of related literature, the researcher developed an individualized self-efficacy enhancing intervention program according to the self-care efficacy theory [15]. The program was designed to include patient's education, empowerment and self-monitoring results of self-care. It guided patients to identify their problems and provided techniques to help them make decisions and take proper actions as they encounter changes in their disease or leg problems. An illustrated handout was also prepared by the researcher to be given to participants in the study group.

\section{Implementation}

The researcher administered the educational intervention to the patients in the study group in the study setting. The training included five efficacy-enhancing sessions at weekly intervals for small group (4-5 patients). The first week session covered information about diabetes, its causes, signs and symptoms, and effects on body system; meaning of diabetic foot, its causes, signs and symptoms and how to avoid; prevention of diabetes complications through self-care, compliance with medication and regular follow-up, and hygienic. This was through a 30-min DVD presentation in Arabic language. The practical part was individual and focused on foot care training (care of skin, nails, between fingers, daily checking, etc.), feet exercise, selection of suitable diet, testing own blood glucose level, and medication intake it take around 60 minute for each patient. The training methods involved questioning, discussion, demonstration and redemonstration. The teaching media included illustrative pictures, video tapes and hand out, By the end of the session, patients received the diabetes self-care illustrated booklet.

During the next four weeks, the researcher conducted four efficacy enhancing small group (4-5 patients) 60-min sessions. The sessions were aimed at fostering self-efficacy enhancing skills, self-goal setting, sharing, and peer support for diabetes. They addressed focusing on patients' agendas, planning personal treatment schedules, defining problems, setting goals, taking a step-by-step approach, brain-storming solutions, considering past efforts successes and failures, and reassessing confidence. The researcher played the role of facilitator through asking questions, and encouraging active participation following the principles of adult learning. Telephone follow-up was started one month after the end of the program and continued for five months to refresh the provided information and booster the program effect. The control group received the routine diabetic care provided to diabetic patients who are at high risk for developing leg problem in the study setting.

\section{Evaluation phase}

The evaluation of the self-efficacy training program on patients clinical health status was carried out. Each patient was assessed one month after implementation of the program (post-test) and six months after the end of the program (follow- up), and their results compared with the pre-test. The same data collection tools were used in the three tests for both groups.

\section{Administrative design and ethical considerations}

The study protocol was approved by the ethics committee at Helwan Faculty of Nursing. The researcher obtained all required official permissions to conduct the study. To be included in the study, an informed consent was obtained from each patient after informing him/her about purpose of the study and the rights to refuse or withdraw at any time with no reasons to be given. Patients' privacy and confidentiality were assured. The study maneuvers could not cause any harmful effect on participants, and professional help was provided to 
Citation: Zeinab Hussen Ali (2016) Effect of Self-Efficacy Enhancing Intervention Training on Clinical Health Status of Diabetic Patients at High-

Page 4 of 9

them as needed. At the end of the study, the program handout was distributed to all patients in both study and control groups.

\section{Statistical analysis}

Data entry and statistical analysis were done using SPSS 20.0 statistical software package. Data were presented using descriptive statistics in the form of frequencies and percentages for qualitative variables, and means and standard deviations and medians for quantitative variables. Quantitative continuous data were compared using the non-parametric Mann-Whitney or Kruskal-Wallis tests. Qualitative categorical variables were compared using chi-square test. Whenever the expected values in one or more of the cells in a $2 \times 2$ tables was less than 5, Fisher exact test was used instead. Spearman rank correlation was used for assessment of the inter-relationships among quantitative variables and ranked ones. Statistical significance was considered at $\mathrm{p}$-value $<0.05$.

\section{Results}

Table 1 demonstrates no statistically significant differences in the socio-demographic characteristics and medical history of the patients in the study and control groups. They had almost equal mean ages (45.4 and 45.1 years, respectively, with slightly more males. The majority of the patients in both groups were married (93.3\%), noneducated, working, and having sufficient income. Only one patient was current smoker, in the study group. As regards their medical history, the duration of diabetes mostly less than 10 years, with means 8.8 and 8.3 respectively. Less than half of them gave a positive family history of diabetes $(46.7 \%$ and $30.0 \%$ respectively). The majority had comorbidities, mostly peripheral vascular diseases. The median number of co-morbidities was 3 in both groups.

\begin{tabular}{|c|c|c|c|c|c|c|}
\hline \multirow{4}{*}{ Items } & \multicolumn{4}{|c|}{ Group } & \multirow{4}{*}{ X2 test } & \multirow{4}{*}{$\begin{array}{l}p- \\
\text { value }\end{array}$} \\
\hline & \multirow{2}{*}{\multicolumn{2}{|c|}{$\begin{array}{l}\text { Study } \\
(n=30)\end{array}$}} & \multirow{2}{*}{\multicolumn{2}{|c|}{$\begin{array}{l}\text { Control } \\
(n=30)\end{array}$}} & & \\
\hline & & & & & & \\
\hline & No. & $\%$ & No. & $\%$ & & \\
\hline \multicolumn{7}{|l|}{ Age: } \\
\hline$<50$ & 19 & 63.3 & 19 & 63.3 & & \\
\hline $50-$ & 11 & 36.7 & 11 & 36.7 & 0 & 1 \\
\hline Range & \multicolumn{2}{|c|}{$28.0-58.0$} & \multicolumn{2}{|c|}{$22.0-56.0$} & & \\
\hline Mean \pm SD & \multicolumn{2}{|c|}{$45.4 \pm 8.2$} & \multicolumn{2}{|c|}{$45.1 \pm 8.8$} & $U=0.01$ & 0.93 \\
\hline Median & \multicolumn{2}{|l|}{44} & \multicolumn{2}{|c|}{46.5} & & \\
\hline \multicolumn{7}{|l|}{ Gender: } \\
\hline Male & 14 & 46.7 & 12 & 40 & & \\
\hline Female & 16 & 53.3 & 18 & 60 & 0.27 & 0.6 \\
\hline \multicolumn{7}{|c|}{ Marital status: } \\
\hline Single & 2 & 6.7 & 2 & 6.7 & & \\
\hline Married & 28 & 93.3 & 28 & 93.3 & Fisher & 1 \\
\hline Education: & & & & & & \\
\hline
\end{tabular}

\begin{tabular}{|c|c|c|c|c|c|c|}
\hline None & 21 & 70 & 19 & 63.3 & & \\
\hline Educated & 9 & 30 & 11 & 36.7 & 0.3 & 0.58 \\
\hline \multicolumn{7}{|l|}{ Job status: } \\
\hline Unemployed & 9 & 30 & 11 & 36.7 & & \\
\hline Working & 21 & 70 & 19 & 63.3 & 0.3 & 0.58 \\
\hline \multicolumn{7}{|l|}{ Smoking: } \\
\hline Current & 1 & 3.4 & 0 & 0 & & \\
\hline Past & 2 & 6.7 & 1 & 3.4 & Fisher & 1 \\
\hline \multicolumn{7}{|l|}{ Income: } \\
\hline Sufficient & 25 & 83.3 & 23 & 76.7 & & \\
\hline Insufficient & 5 & 16.7 & 7 & 23.3 & 0.42 & 0.52 \\
\hline \multicolumn{7}{|l|}{$\begin{array}{l}\text { Duration } \\
\text { (years): }\end{array}$} \\
\hline$<10$ & 18 & 60 & 20 & 66.7 & & \\
\hline $10+$ & 12 & 40 & 10 & 33.3 & 0.29 & 0.59 \\
\hline Range & \multicolumn{2}{|c|}{$3.0-20.0$} & \multicolumn{2}{|c|}{$3.0-20.0$} & & \\
\hline Mean \pm SD & \multicolumn{2}{|c|}{$8.8 \pm 4.7$} & \multicolumn{2}{|c|}{$8.3 \pm 5.4$} & $\mathrm{U}=0.76$ & 0.38 \\
\hline Median & \multicolumn{2}{|l|}{7} & \multicolumn{2}{|l|}{6.5} & & \\
\hline \multicolumn{7}{|l|}{ Have: } \\
\hline Positive family history & 14 & 46.7 & 9 & 30 & 1.76 & 0.18 \\
\hline Hypertension & 24 & 80 & 23 & 76.7 & 0.1 & 0.75 \\
\hline High cholesterol & 25 & 83.3 & 26 & 86.7 & Fisher & 1 \\
\hline $\begin{array}{l}\begin{array}{l}\text { Peripheral vascular } \\
\text { disease }\end{array} \\
\text { a }\end{array}$ & 27 & 90 & 30 & 100 & Fisher & 0.24 \\
\hline \multicolumn{7}{|l|}{ Total co-morbidities: } \\
\hline Range & \multicolumn{2}{|l|}{$1-3$} & \multicolumn{2}{|l|}{$1-3$} & & \\
\hline Mean \pm SD & \multicolumn{2}{|c|}{$2.5 \pm 0.7$} & \multicolumn{2}{|c|}{$2.6 \pm 0.7$} & $U=0.53$ & 0.47 \\
\hline Median & \multicolumn{2}{|l|}{3} & \multicolumn{2}{|l|}{3} & & \\
\hline
\end{tabular}

Table 1: Socio-Demographic and Medical Characteristics of Patients in the Study and Control Groups; (U) Mann-Whitney test.

The comparison of the lower limbs clinical manifestation among the patients in the study and control groups throughout the phases of the study (Table 2) revealed no statistically significant differences at the pre-intervention phase. At the post-intervention phase, the patients in the study group had significantly lower percentages of abnormal skin changes $(p<0.001)$, lower limbs edema $(p<0.001)$, and abnormal sensation $(p<0.001)$. At the follow-up phase, they had significantly lower percentages of all abnormal lower limb findings $(p<0.001)$, compared with those in the control group. In total, $40.0 \%$ of the patients in the study group had abnormal findings at the follow-up phase, compared with $96.7 \%$ of those in the control group $(\mathrm{p}<0.001)$. 
Citation: Zeinab Hussen Ali (2016) Effect of Self-Efficacy Enhancing Intervention Training on Clinical Health Status of Diabetic Patients at HighRisk for Leg Problems. J Pat Care 2: 111. doi:10.4172/2573-4598.1000111

Page 5 of 9

\begin{tabular}{|c|c|c|c|c|c|c|}
\hline \multirow{4}{*}{ Item } & \multicolumn{4}{|c|}{ Group } & \multirow[b]{2}{*}{$\mathrm{X} 2$ test } & \multirow[b]{2}{*}{ p-value } \\
\hline & \multicolumn{2}{|c|}{ Study } & \multicolumn{2}{|c|}{ Control } & & \\
\hline & \multicolumn{2}{|c|}{$(n=30)$} & \multicolumn{2}{|c|}{$(n=30)$} & & \\
\hline & No. & $\%$ & No. & $\%$ & & \\
\hline \multicolumn{7}{|c|}{ Abnormal pulses of lower limbs: } \\
\hline Pre & 30 & 100 & 29 & 96.7 & Fisher & 1 \\
\hline Post & 24 & 80 & 28 & 93.3 & Fisher & 0.25 \\
\hline FU & 4 & 13.3 & 28 & 93.3 & 38.57 & $<0.001^{*}$ \\
\hline \multicolumn{7}{|c|}{ Abnormal skin changes: } \\
\hline Pre & 30 & 100 & 30 & 100 & 0 & 1 \\
\hline Post & 12 & 40 & 29 & 96.7 & 22.26 & $<0.001^{*}$ \\
\hline FU & 3 & 10 & 29 & 96.7 & 45.27 & $<0.001^{*}$ \\
\hline \multicolumn{7}{|l|}{ Pain: } \\
\hline Pre & 30 & 100 & 29 & 96.7 & Fisher & 1 \\
\hline Post & 24 & 80 & 28 & 93.3 & Fisher & 0.25 \\
\hline FU & 8 & 26.7 & 28 & 93.3 & 27.78 & $<0.001^{*}$ \\
\hline \multicolumn{7}{|c|}{ Lower limbs edema: } \\
\hline Pre & 30 & 100 & 28 & 93.3 & Fisher & 0.49 \\
\hline Post & 13 & 43.3 & 29 & 96.7 & 20.32 & $<0.001^{*}$ \\
\hline FU & 2 & 6.7 & 28 & 93.3 & 45.07 & $<0.001^{*}$ \\
\hline \multicolumn{7}{|c|}{ Abnormal sensation (touch, temperature): } \\
\hline Pre & 30 & 100 & 30 & 100 & 0 & 1 \\
\hline Post & 13 & 43.3 & 29 & 96.7 & 20.32 & $<0.001^{*}$ \\
\hline FU & 2 & 6.7 & 29 & 96.7 & 48.65 & $<0.001^{*}$ \\
\hline \multicolumn{7}{|c|}{ Total lower limbs disorders: } \\
\hline Pre & 30 & 100 & 30 & 100 & 0 & 1 \\
\hline Post & 26 & 86.7 & 30 & 100 & Fisher & 0.11 \\
\hline FU & 12 & 40 & 29 & 96.7 & 22.26 & $<0.001^{*}$ \\
\hline
\end{tabular}

Table 2: Percentage distribution of patients in both groups (Study and Control) according to their lower limbs Clinical manifestation at different intervals; $\left(^{*}\right)$ Statistically significant at $\mathrm{p}<0.05$.

As regards the changes in patients' self-care practices throughout the study phases, Table 3 demonstrates no statistically significant differences between the study and control groups at the preintervention phase. The only exception was the more days of intake of medications last week in the control group ( $\mathrm{p}=0.003$ ), indicating better compliance. At the post-intervention phase, the patients in the study group had significantly better compliance with medications, more days of intake of medications, of following diet, exercise, and practicing foot care during last week $(\mathrm{p}<0.001)$. These differences continued to the follow-up phase, in addition a significantly higher percentage of patients testing their blood glucose $(\mathrm{p}=0.03)$. Meanwhile, the table indicates no statistically significant differences between the study and control groups in their BMI at any of the study phases. 
Citation: Zeinab Hussen Ali (2016) Effect of Self-Efficacy Enhancing Intervention Training on Clinical Health Status of Diabetic Patients at HighRisk for Leg Problems. J Pat Care 2: 111. doi:10.4172/2573-4598.1000111

Page 6 of 9

\begin{tabular}{|c|c|c|c|c|c|c|c|c|c|}
\hline & \multicolumn{3}{|l|}{ Pre (\%) } & \multicolumn{3}{|l|}{ Post (\%) } & \multicolumn{3}{|l|}{ FU (\%) } \\
\hline & Study & Control & p- & Study & Control & p- & Study & Control & p- \\
\hline & $(n=30)$ & $(n=30)$ & value & $(n=30)$ & $(n=30)$ & value & $(n=30)$ & $(n=30)$ & value \\
\hline Medications compliance & 3.3 & 3.3 & -- & 90 & 23.3 & $<0.001^{*}$ & 70 & 20 & $<0.001^{*}$ \\
\hline \multicolumn{10}{|l|}{ Days taken last week: } \\
\hline Range & $0.0-3.0$ & $0.0-7.0$ & & $2.0-7.0$ & $0.0-7.0$ & & $3.0-7.0$ & $0.0-7.0$ & \\
\hline Mean \pm SD & $1.0 \pm 1.1$ & $2.8 \pm 2.4$ & $0.003^{*}$ & $6.7-1.0$ & $3.8-2.5$ & $<0.001^{*}$ & $6.3 \pm 1.2$ & $4.1 \pm 2.3$ & $<0.001^{*}$ \\
\hline Median & 0.5 & 3 & & 7 & 3.5 & & 7 & 4 & \\
\hline \multicolumn{10}{|l|}{ Diet (days last week): } \\
\hline Range & $0.0-4.0$ & $0.0-3.0$ & & $3.0-6.0$ & $0.0-5.0$ & & $3.0-5.0$ & $0.0-4.0$ & \\
\hline Mean \pm SD & $1.8 \pm 1.0$ & $1.9 \pm 1.0$ & 0.44 & $4.7 \pm 0.8$ & $2.2 \pm 1.3$ & $<0.001^{*}$ & $3.8 \pm 0.5$ & $1.7 \pm 1.3$ & $<0.001^{*}$ \\
\hline Median & 2 & 2 & & 5 & 2.5 & & 4 & 2 & \\
\hline \multicolumn{10}{|c|}{ Exercise (Days last week): } \\
\hline Range & $0.0-2.0$ & $0.0-1.0$ & & $1.0-7.0$ & $0.0-3.0$ & & $0.0-6.0$ & $0.0-0.0$ & \\
\hline Mean \pm SD & $0.1 \pm 0.4$ & $0.0 \pm 0.2$ & 0.98 & $3.3 \pm 1.5$ & $0.2 \pm 0.6$ & $<0.001^{*}$ & $3.1 \pm 1.6$ & $0.0 \pm 0.0$ & $<0.001^{*}$ \\
\hline Median & 0 & 0 & & 3 & 0 & & 3 & 0 & \\
\hline Tested blood glucose & 26.7 & 26.7 & 0.54 & 86.7 & 73.3 & 0.2 & 80 & 53.3 & $0.03^{*}$ \\
\hline \multicolumn{10}{|l|}{ Days last week: } \\
\hline Range & $1.0-4.0$ & $1.0-5.0$ & & $1.0-5.0$ & $1.0-5.0$ & & $1.0-6.0$ & $1.0-5.0$ & \\
\hline Mean \pm SD & $2.7 \pm 1.0$ & $2.8 \pm 1.3$ & 0.95 & $2.6 \pm 1.1$ & $2.4 \pm 1.3$ & 0.37 & $2.2 \pm 1.1$ & $2.0 \pm 1.1$ & 0.47 \\
\hline Median & 3 & 2.5 & & 2 & 2 & & 2 & 2 & \\
\hline \multicolumn{10}{|c|}{ Foot care (days last week): } \\
\hline Range & $0.0-1.0$ & $0.0-1.0$ & & $3.0-7.0$ & $0.0-5.0$ & & $2.0-7.0$ & $0.0-3.0$ & \\
\hline Mean \pm SD & $0.0 \pm 0.2$ & $0.1 \pm 0.3$ & 0.3 & $6.0 \pm 0.9$ & $0.2 \pm 0.9$ & $<0.001^{*}$ & $5.0 \pm 1.1$ & $0.6 \pm 0.8$ & $<0.001^{*}$ \\
\hline Median & 0 & 0 & & 6 & 0 & & 5 & 0 & \\
\hline \multicolumn{10}{|l|}{ BMI: } \\
\hline$<25$ & 13.3 & 20 & & 20 & 20 & & 20 & 20 & \\
\hline $25-$ & 30 & 23.3 & 0.72 & 33.3 & 26.7 & 0.84 & 33.3 & 26.7 & 0.84 \\
\hline $30+$ & 56.7 & 56.7 & & 46.7 & 53.3 & & 46.7 & 53.3 & \\
\hline
\end{tabular}

Table 3: Self-care practices and Body Mass Index (BMI) for Patients in the study and control groups throughout the study period, $\left(^{\star}\right)$ statistically significant at $\mathrm{p}<0.05$.

Table 4 shows no statistically significant differences between the patients in the study and control groups' health perception, selfconfidence, or in their clinical/laboratory findings at the preintervention phase. At the post-intervention phase, the patients in the study group had significantly less low perception of health and higher self-confidence score $(p<0.001)$. They also had higher percentages of normal systolic $(\mathrm{p}<0.001)$ and diastolic $(\mathrm{p}=0.01)$ blood pressure, and lower percentage of hypertension $(\mathrm{p}<0.001)$. As for the lab results, they had higher percentages of normal random blood sugar $(\mathrm{p}<0.001)$, glycated $\mathrm{Hb} \quad(\mathrm{p}<0.001)$, and total cholesterol $(\mathrm{p}=0.001)$. These statistically significant improvements continued throughout the follow-up phase. Meanwhile, no significant differences could be revealed in patients' serum creatinine or blood urea. 
Citation: Zeinab Hussen Ali (2016) Effect of Self-Efficacy Enhancing Intervention Training on Clinical Health Status of Diabetic Patients at High-

Page 7 of 9

\begin{tabular}{|c|c|c|c|c|c|c|c|c|c|}
\hline \multirow[b]{2}{*}{ Items } & \multicolumn{3}{|l|}{ Pre $(\%)$} & \multicolumn{3}{|l|}{ Post (\%) } & \multicolumn{3}{|l|}{ FU (\%) } \\
\hline & Study & Control & $\mathrm{p}-$ & Study & Control & $\mathrm{p}-$ & Study & Control & $\mathrm{p}-$ \\
\hline & $(n=30)$ & $(n=30)$ & value & $(n=30)$ & $(n=30)$ & value & $(n=30)$ & $(n=30)$ & value \\
\hline $\begin{array}{l}\text { Low health perception Self- } \\
\text { confidence score }(\max =10) \text { : }\end{array}$ & 90 & 96.7 & 0.61 & 60 & 96.7 & $<0.001^{*}$ & 6.7 & 93.3 & $<0.001^{*}$ \\
\hline Range & $1.0-8.6$ & $1.0-1.4$ & & $5.4-10$ & $1.0-9.1$ & & $3.8-10$ & $1.0-3.6$ & \\
\hline Mean \pm SD & $1.3 \pm 1.4$ & $1.0 \pm 0.1$ & 0.59 & $9.2 \pm 1.1$ & $1.5 \pm 1.5$ & $<0.001^{*}$ & $8.5 \pm 1.5$ & $1.6 \pm 0.7$ & $<0.001^{*}$ \\
\hline Median & 1 & 1 & & 9.94 & 1 & & 9.07 & 1.07 & \\
\hline \multicolumn{10}{|l|}{ Normal: } \\
\hline Systolic blood pressure & 33.3 & 36.7 & 0.79 & 90 & 36.7 & $<0.001^{*}$ & 96.7 & 50 & $<0.001^{*}$ \\
\hline Diastolic blood pressure & 26.7 & 40 & 0.27 & 73.3 & 40 & $0.01^{*}$ & 90 & 36.7 & $<0.001^{*}$ \\
\hline Hypertension & 73.3 & 70 & 0.77 & 26.7 & 73.3 & $<0.001^{*}$ & 10 & 66.7 & $<0.001^{*}$ \\
\hline S. creatinine & 26.7 & 36.7 & 0.41 & 40 & 26.7 & 0.27 & 40 & 36.7 & 0.79 \\
\hline Blood urea & 100 & 100 & 1 & 100 & 100 & 1 & 100 & 96.7 & 1 \\
\hline Random blood sugar & 10 & 6.7 & 1 & 80 & 10 & $<0.001^{*}$ & 83.3 & 13.3 & $<0.001^{*}$ \\
\hline Glycated $\mathrm{Hb}$ & 60 & 40 & 0.12 & 100 & 33.3 & $<0.001^{*}$ & 100 & 6.7 & $<0.001^{*}$ \\
\hline Total cholesterol & 10 & 3.3 & 0.61 & 40 & 3.3 & $0.001^{*}$ & 43.3 & 6.7 & $0.001^{*}$ \\
\hline
\end{tabular}

Table 4: Perception of Health, Self-Confidence, and Lab Results in the Study and Control Groups throughout the Study Phases, $\left({ }^{*}\right)$ statistically significant at $\mathrm{p}<0.05$.

Figure 1 illustrates statistically significant and larger increases in patients' self-confidence, and foot self-care scores as well as the glycated hemoglobin (HbAlc) levels in the study group. In the control group, there was a significant but trivial increase in the self-confidence score, but significant decrease in their foot self-care score, with significant deterioration of their HbAlc levels.

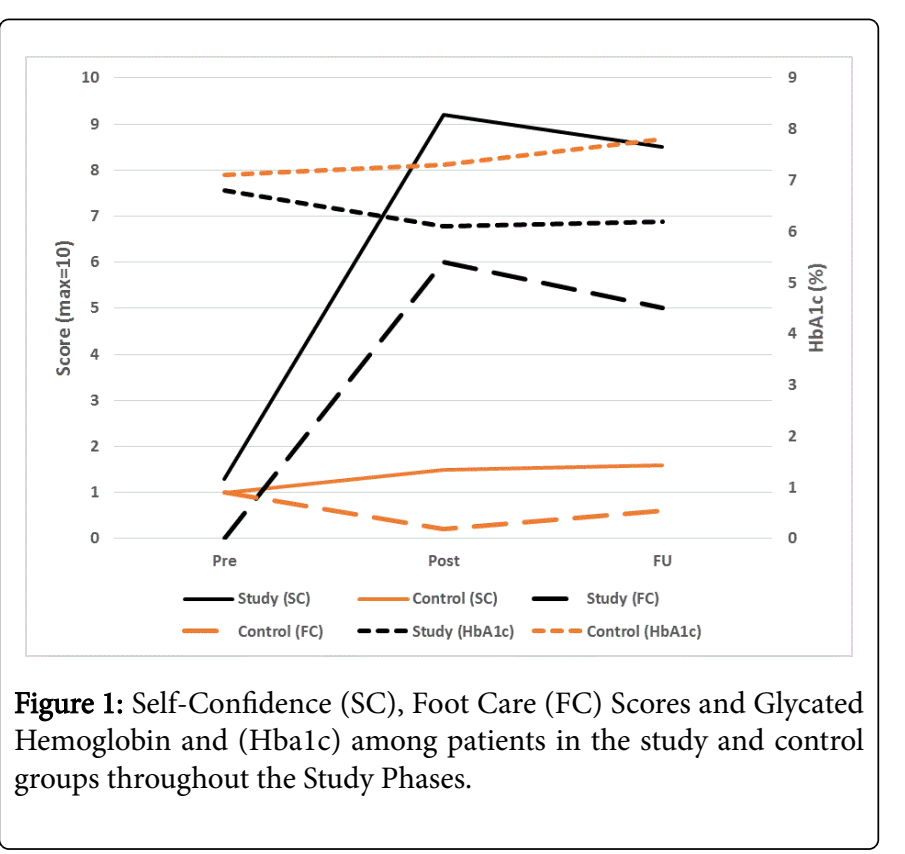

Table 5 illustrates the presence of a statistically significant strong positive correlation between the scores of self-confidence and foot selfcare $(r=0.96)$, and moderate positive correlation between the number of abnormal signs and the level of HbAlc. Meanwhile, the total number of abnormal signs correlated negatively and strongly with the score of self-confidence and foot self-care. As for the level of HbAlc, it correlated moderately and negatively with the scores of self-confidence and foot self-care.

\begin{tabular}{|l|c|c|c|c|}
\hline \multirow{2}{*}{\multicolumn{1}{|c|}{ Items }} & \multicolumn{3}{|c|}{ Spearman's rank correlation coefficient } \\
\cline { 2 - 5 } & $\begin{array}{c}\text { Total } \\
\text { abnormal } \\
\text { signs }\end{array}$ & $\begin{array}{c}\text { Foot } \\
\text { care }\end{array}$ & $\begin{array}{c}\text { Self- } \\
\text { confidence }\end{array}$ & HbA1c \\
\hline Total abnormal signs & $-0.70^{* *}$ & & & \\
\hline Foot care & $-0.71^{* *}$ & $0.96^{* *}$ & & \\
\hline Self-confidence & $0.47^{* *}$ & $-0.56^{* *}$ & $-0.57^{* *}$ & \\
\hline HbA1c & & & \\
\hline
\end{tabular}

Table 5: Correlation matrix of clinical exam, foot care, self-confidence scores and glycated Hemoglobin (HbAlc), ${ }^{* *}$ ) statistically significant at $\mathrm{p}<0.01$.

\section{Discussion}

Diabetes education is now considered an integral part of diabetes care. Diabetes self-management education assists people in coping with the mental and physical demands of their illness, given their 
unique economic, cultural and social circumstances [24]. Improved self-efficacy in diabetic foot self-care for those at risk of complications represents an avenue toward prevention of unnecessary lower limb amputation [25]. The present study findings support this and lead to accepting its research hypotheses since the diabetic patients who attended the self-care program showed better compliance, undertook diabetic self-care activities more frequently, and had better lower limbs health status, as well as certain clinical and laboratory findings.

The current study used a robust research design, namely the randomized controlled trial, which provides a very high level of evidence $[26,27]$. The application of the randomization process in the current study was successful as shown by the absence of any significant differences in the socio-demographic and medical characteristics of the patients in the study and control groups. The percentage of women in both groups was slightly higher, which is in congruence with the known gender distribution, with higher prevalence among females [28]. There was also a high percentage of positive family history in the two groups, which goes in line with the findings of a recent study in Minia Governorate [29]. Moreover, there was a very high prevalence of associated cardiovascular diseases among the patients in both groups, which is expected given that they were all at high risk for diabetes foot problems as shown by Wu et al in 2015 [30] in a study in China.

More importantly, the patients in the two groups of the present study had similar risk factors for developing diabetic foot ulcers at the baseline assessment before the intervention. Thus, they had no significant differences in their peripheral pulses, skin changes, pain, edema, or abnormal sensations. This similarity is crucial since they represent the most important predictors of diabetic foot ulcer as demonstrated by Crawford et al in a recent systematic review. Meanwhile, the implementation of the study intervention led to significant improvements in these risk factors, which was most evident at the 6-month follow-up where the prevalence of abnormal leg problems dropped to two-fifth compared to $100 \%$ at the pre-test and in the control group. A similar success of an educational intervention in the prevention of diabetic foot was reported in a study in Italy [31].

The success of the current study intervention in improving the health status of the diabetic patients' legs and feet can be attributed to the effect of the self-efficacy enhancement by the program, which was shown to have a significant improvement among the patients in the study group at the post and follow-up tests. In congruence with this, a study in Iran demonstrated significant improvements in diabetic patients' self-efficacy following an educational intervention program [32]. The improvement in self-confidence and self-efficacy of the studied patients led to better self-care practices. In fact, the results demonstrated significant improvements in patients' compliance to intake of medications, following dietary regimen, practicing exercise and foot care, and testing own blood glucose in the study group after the intervention.

Moreover, the self-confidence score was positively correlated to the foot care score, and negatively correlated to the number of abnormal signs in the legs and feet. This adds to the evidence that increasing diabetic patient's self-confidence and self-efficacy is of great importance in improving his/her outcomes. In agreement with this, a study in Taiwan gave evidence of the positive effect of increasing diabetic patients' self-efficacy on their practice of foot care [33].

The present study has also provided objective evidence of the effectiveness of the intervention program in improving diabetic patients' health status. This was demonstrated through the clinical and laboratory findings, such as the improvements in the blood pressure, as well as the levels of random blood sugar glycated $\mathrm{Hb}$, and total cholesterol at the post and follow-up phases. These are certainly secondary to the increased patients' self-confidence and efficacy, with subsequent better self-care practices. These changes would induce such beneficial changes in patients' clinical and laboratory parameters. Additionally, the current study revealed a significant negative correlation between patients' self-confidence score and their glycated $\mathrm{Hb}$ level. Thus, a more self-confident patient would have better selfcare practices that lead to better glycemic control. In line with this, a recent study in Taiwan set a valid model showing the influence of empowerment perceptions, self-efficacy, and self-care behaviors on the control of glycated hemoglobin (HbA1c) levels in patients with type 2 diabetes [34]. Additionally, Gao et al in 2013 [35] in China and Walker et al in 2014 in the United States found that the patients with higher self-efficacy had better control of their HbAlc.

\section{Conclusion and Recommendations}

Increasing diabetic patients' self-confidence and self-efficacy can improve their self-care practices, with subsequent positive impacts on their general and feet health status and diabetic control. Therefore, the implementation of self-efficacy enhancing training programs for those patients is recommended, with the use of the developed illustrated booklet as an educational aid. This should be generalized in hospitals for teaching diabetic patients at risk for lower limb problems. It is also important that all health care team members give more emphasis to their roles as patient educators. More research is needed to investigate the long-term effect of such educational interventions.

\section{References}

1. Chaturvedi N (2007) The burden of diabetes and its complications: trends and implications for intervention. Diabetes Res Clin Pract 76 Suppl 1: S3-12.

2. Seclen SN, Rosas ME, Arias AJ, Huayta E, and Medina CA (2015) Prevalence of diabetes and impaired fasting glucose in Peru: report from PERUDIAB, a national urban population-based longitudinal study. BMJ Open Diabetes Res Care 3:e000110.

3. Zhang Y, Chen H, Lu H, Shen Y, Chen R, et al. (2015) Prevalence and risk of diabetes based on family history in the Shanghai High-Risk Diabetic Screen (SHiDS) study. Diabet Med .

4. Hopkins RB, Burke N, Harlock J, et al. (2015) Economic burden of illness associated with diabetic foot ulcers in Canada. BMC Health Serv Res 15: 13.

5. Humphries MD, Brunson A, Hedayati N, Romano P, Melnkow J (2016) Amputation Risk in Patients with Diabetes Mellitus and Peripheral Artery Disease Using Statewide Data. Ann Vasc Surg 30: 123-131.

6. Apelqvist J, Bakker K, van Houtum WH, Schaper NC; International Working Group on the Diabetic Foot (IWGDF) Editorial Board (2008) Practical guidelines on the management and prevention of the diabetic foot: based upon the International Consensus on the Diabetic Foot (2007) Prepared by the International Working Group on the Diabetic Foot. Diabetes Metab Res Rev 24 Suppl 1: S181-187.

7. Wang DD, Jamjoom RA, Alzahrani AH, Hu FB, Alzahrani HA (2016) Prevalence and Correlates of Lower-Extremity Amputation in Patients With Diabetic Foot Ulcer in Jeddah, Saudi Arabia. Int J Low Extrem Wounds 15: 26-33

8. Ahmad J (2015) The diabetic foot. Diabetes Metab Syndr.

9. Urant CF (2008) Medical management of type 2 diabetes. 6th edition. Alexandria, VA: American Diabetes Association.

10. American Diabetes Association (2012) Standards of medical care in diabetes--2012. Diabetes Care 35 Suppl 1: S11-63. 
Citation: Zeinab Hussen Ali (2016) Effect of Self-Efficacy Enhancing Intervention Training on Clinical Health Status of Diabetic Patients at HighRisk for Leg Problems. J Pat Care 2: 111. doi:10.4172/2573-4598.1000111

Page 9 of 9

11. Isiguzo CM, Jac-Okereke C (2015) DIABETIC FOOT ULCERS -12 MONTHS PROSPECTIVE REVIEW OF PATTERN OF PRESENTATION AT ENUGU STATE UNIVERSITY OF TECHNOLOGY TEACHING HOSPITAL, PARKLANE, ENUGU: A BASIS FOR DIABETIC FOOT CLINIC? Niger J Med 24: 125-130.

12. Van Netten JJ, Price PE, Lavery LA, Monteiro-Soares M, Rasmussen A, Jubiz Y, Bus SA, International Working Group on the Diabetic Foot (IWGDF) (2015) Prevention of foot ulcers in the at-risk patient with diabetes: a systematic review. Diabetes Metab Res Rev.

13. Bell RA, Arcury TA, Snively BM, Smith SL, Stafford JM, et al. (2005) Diabetes foot self-care practices in a rural triethnic population. Diabetes Educ 31: 75-83.

14. Prompers L, Huijberts M, Apelqvist J, Jude E, Piaggesi A, et al. (2007) High prevalence of ischaemia, infection and serious comorbidity in patients with diabetic foot disease in Europe. Baseline results from the Eurodiale study. Diabetologia 50: 18-25.

15. Luo X, Liu T, Yuan X, Ge S, Yang J, et al. (2015) Factors Influencing SelfManagement in Chinese Adults with Type 2 Diabetes: A Systematic Review and Meta-Analysis. Int $\mathrm{J}$ Environ Res Public Health 12 11304-11327.

16. Dorresteijn JA, Kriegsman DM, Assendelft WJ, Valk GD (2014) Patient education for preventing diabetic foot ulceration. Cochrane Database Syst Rev.

17. International Diabetes Federation (2012) Diabetes atlas.

18. Wild S, Roglic G, Green A, Sicree R, King H (2004) Global prevalence of diabetes: estimates for the year 2000 and projections for 2030. Diabetes Care 27: 1047-1053.

19. Shankar EM, Mohan V, Premalatha G, Srinivasan RS, Usha AR (2005) Bacterial etiology of diabetic foot infections in South India. Eur J Intern Med 16: 567-570.

20. Citron DM, Goldstein EJ, Merriam CV, Lipsky BA, Abramson MA (2007) Bacteriology of moderate-to-severe diabetic foot infections and in vitro activity of antimicrobial agents. J Clin Microbiol 45: 2819-2828.

21. Bandura A (1997) Self-efficacy the exercise of control NY: W.H. Freeman and Company.

22. Bandura A (1985) Social foundations of thought and action Upper Saddle, NJ: Prentice Hall.

23. La Clinica de La Raza (2009) Advancing diabetes self-management.

24. Allgot B, Gan D, King H, Lefèbvre P, Mbanya JC, et al. (2013) Diabetes Atlas, Second edition, and other IDF publications are available from:
International Diabetes Federation Executive Office,19 Avenue Emile de Mot, B-1000 version of Diabetes Atlas.

25. Wendling S, and Beadle V (2015) The relationship between self-efficacy and diabetic foot self-care, journal of clinical and transitional endocrinology 2: 37-41.

26. Burns PB, Rohrich RJ, Chung KC (2011) The levels of evidence and their role in evidence-based medicine. Plast Reconstr Surg 128: 305-310.

27. Twells LK (2015) Evidence-based decision-making 1: Critical appraisal. Methods Mol Biol 1281: 385-396.

28. Butala NM, Desai MM, Linnander EL, Wong YR, Mikhail DG, et al. (2011) Gender differences in presentation, management, and in-hospital outcomes for patients with AMI in a lower-middle income country: evidence from Egypt. PLoS One 6:e25904.

29. Ali BA, Abdallah ST, Abdallah AM, Hussein MM (2013) The Frequency of Type 2 Diabetes Mellitus among Diabetic Children in El Minia Governorate, Egypt. Sultan Qaboos Univ Med J 13: 399-403.

30. Wu L, Hou Q, Zhou Q, Peng F (2015) Prevalence of risk factors for diabetic foot complications in a Chinese tertiary hospital. Int J Clin Exp Med 8: 3785-3792.

31. Monami M, Zannoni S, Gaias M, Nreu B, Marchionni N, et al. (2015) Effects of a Short Educational Program for the Prevention of Foot Ulcers in High-Risk Patients: A Randomized Controlled Trial. Int J Endocrinol 2015: 615680 .

32. Seyyedrasooli A, Parvan K, Valizadeh L, Rahmani A, Zare M, et al. (2015) Self-efficacy in foot-care and effect of training: a single-blinded randomized controlled clinical trial. Int J Community Based Nurs Midwifery 3: 141-149.

33. Chin YF, Huang TT, and Hsu BR (2013) Impact of action cues, selfefficacy and perceived barriers on daily foot exam practice in type 2 diabetes mellitus patients with peripheral neuropathy. J Clin Nurs 22: 61-8.

34. Lee YJ, Shin SJ, Wang RH, Lin KD, Lee YL, et al. (2016) Pathways of empowerment perceptions, health literacy, self-efficacy, and self-care behaviors to glycemic control in patients with type 2 diabetes mellitus. Patient Educ Couns 99: 287-294.

35. Gao J, Wang J, Zheng P, Haardörfer R, Kegler MC, et al. (2013) Effects of self-care, self-efficacy, social support on glycemic control in adults with type 2 diabetes. BMC Fam Pract 14: 66 . 